

\title{
Linguoculturological Features Of The Problem Of Communication
}

\section{Shirinxon Hakimovna Alpanova}

Doctor Of Philosophy In Philology (Phd), Lecturer, Department Of Uzbek Linguistics, Andijan State University, Uzbekistan

\section{ABSTRACT}

The article describes the lingvoculturological aspects of speech activity. Views on aspects of communicative behavior related to the national character, as well as its relation to human psychology and physiology, were evaluated as an anthropocentric approach to the language system.

\section{KEYWORDS}

Linguoculturology, cognitive linguistics, pragmatics, synchronous, diachronic, psycholinguistics, discourse, object, subject.

\section{INTRODUCTION}

In the first years of the XXI century, research based on the anthropocentric paradigm began to play an important role in Uzbek linguistics. This work is significant in that it is mainly carried out in new areas such as sociolinguistics, cognitive linguistics, linguistic pragmatics, and psycholinguistics. Although the focus on the person who created the text was originally seen in psycholinguistics and pragmalinguistics, the rapidly evolving fields 
of cognitive linguistics, ethnolinguistics, linguoculturology, and discursive analysis have made it one of the central problems of linguistics.

There are also different views on the object of study of linguoculturology. For example, according to V.N. Telia, linguoculturology studies only the synchronous connection of language and culture. [1,222] V.A. Maslova believes that this field studies language both synchronously and diachronically. [2.208] Also, V.N. While Telia emphasizes that the object of linguoculturology has a universal character, V.A. Maslova emphasizes that the linguoculturological features of the language of a particular people or fraternal peoples should be studied separately.

Verbal communication is a product of human activity. Subjectivity in human activity, that is, objective for man - the separation of aspects specific to the being outside of man, the distinction between them is called subjectivity in the process of activity. Philosophers, psychologists, and linguists have differing views on the study of the interdependence of subjectivity and objectivity. Indeed, human activity reflects the unique characteristics of each individual. It can be concluded from this that human activity is essentially subjective. Although the activity is performed by individual individuals, the activity is read, evaluated, and awakened in it by other individuals.

\section{ANALYSIS AND RESULTS}

It is well known that the formation of speech units and their understanding is the result of mental activity. The performance of this activity is directly related to the condition of having linguistic knowledge. Because without linguistic knowledge it is impossible to know the reality, to linguistically express the logical structures that reflect the information about the events. It is no coincidence, therefore, that cognitive linguistics is seen as a science that explains the composition of linguistic ability. [3.17]

The study of the text and the personality factor that perceives it requires an approach to the object of study from various aspects, in particular, from a semantic, psychological, pragmatic, cognitive and lingvoculturological perspective. The study of the writer (or speaker) factor in text creation also leads to a deeper understanding of the issue of individual style. After all, in our linguistics, the style of a particular writer or poet is studied mainly on the example of the word and speech level. This kind of approach to the individual style often does not fully reflect all aspects of the creative style.

In the words of $\mathrm{NI}$ Jinkin: "Man speaks through the text, not through individual words" [4.108] Therefore, the expected results can be achieved only if the style of a particular person is studied on the basis of the texts he created. The way a writer or creator explores his or her speech style in terms of his or her word usage or sentence composition skills does not meet today's demand. Therefore, the study of the issue of text creation in terms of personality style is one of the current problems of linguistics.

SM Muminov's doctoral dissertation on "Socio-linguistic features of Uzbek communication behavior" examines the specific communication behavior of Uzbeks from a socio-linguistic point of view. The study also contains views on aspects of communicative behavior related to the national character, as well as its relationship to human psychology and physiology, which 
can be assessed as an anthropocentric approach to the language system. "The problem of communication cannot be studied without taking into account the national character, the unique customs, values and traditions of the people of the nation. The linguistic view of the world is "a set of conventional and obligatory methods of perceiving the world that are historically formed in the mind of a particular language community, stabilized in its language, and specific to that community; is a set of universal and at the same time nationally adapted methods of perception and conceptualization of the universe. "[5.56] The Linguistic Landscape of the Universe performs the following tasks: Linguistic conceptualization is seen as a process because it is a dynamic system in which some parts of the linguistic landscape of the world can appear, become clear, or blur over time ". [6.12]

Undoubtedly, the main purpose of the process of communication is the transmission and reception of information. But the purpose of communication is not limited to the exchange of information, the purpose of communication is to influence the "partner", to convince him of something, to subdue, to motivate him to action. We also know that semiotics, as they themselves admit, are also used by the speaker as a means of communication to express their inclinations, likes, dislikes, surprises, and other emotional feelings. Only when the same aspects of linguistic communication are taken into account can it be imagined that the parts of the semiotic system are in a dynamic, dynamic relationship with each other. [7.28]

The diversity of tasks performed in the process of linguistic communication is recognized by many. Opinions about the amount of tasks that can be performed also vary. [8.59]

People's knowledge of reality may vary subjectively, but it should also be borne in mind that individuals living in a single environment follow principles and rules that are common to that environment. The same thing leads to a peculiar 'interpersonal agreement' in the perception of reality by the persons in communication. Communication requires partial alternative and partial nonalternative in the subjective perception of reality

While language allows people to communicate with each other, it always reveals the jewels it hides in its bosom, like the ocean. Linguistic and cognitive processes combine to form a single speech thinking. Therefore, the main condition for the realization of speech activity is the linguistic knowledge accumulated by each person throughout his life and the linguistic ability formed during his life. In the words of Professor N.Mahmudov, a fan of our language, "The peculiarity of the way of thinking realized through language is the peculiarity of seeing and perceiving existence in a certain sense. Every nation sees, hears and enjoys itself." That is, the uniqueness of each nation is reflected in its way of life, level of thinking, linguistic knowledge and ability.

Implicitism has been one of the important features of verbal communication. This feature is especially evident in the semantics of the literary text. According to many researchers who have analyzed artistic speech, the more hidden the idea expressed in the text, the more influential it will be. [9.136] One of the interesting things is that a person can never express the most delicate feelings and intimate feelings that he cherishes in the 
depths of his heart, looking directly at his lover or lover. This is especially true for Uzbeks who adhere to centuries-old values and traditions. It seems easier and more convenient to express by leaving a voice message on the phone. If there is no choice but to speak face to face, he involuntarily turns to another language - Russian, English, French, Persian, Arabic... There are many examples of Uzbek literature in world literature. There are many examples of love conflicts in LN Tolstoy's "War and Peace", "Anna Karenina", Pushkin's "Eugene Onegin", Turgenev, Dostoevsky. We refer to the novel "Equilibrium" by Ulugbek Hamdam. "Yusuf called Zahra the same day.

"I know the reason for the emergency meeting," said Zahro, as they drank Coca-Cola in a crowded cafe.

"What is it?" - Joseph asked despite the fact that the woman was right.

- Why do you ask, we both know that you want to break up with me.

- What do you think about that? Yusuf involuntarily followed Zahra and spoke in Russian, at the same time he thought: "Why Russian? Is it a sign of culture, a desire for diversity, or do ideas in Russian come out bold and fluent? Maybe it's an attempt to hide your guilt and shame behind another language because it's an unethical attitude? Is it the nobility that I have violated my morals, that my tongue should not be defiled?

... They walked quietly and set out on the main road.

Joseph stopped one of the cars.

"Shall I follow you?"

- I do not want myself ... Zahra asked as she sat in the car:

- You will call?
"I don't know if I can do it."

"Good-bye." Zahra turned her face to the dark side of the car.

"All right, go," said Yusuf, "I didn't know why he said goodbye to you." [10.179]

Joseph was the strongest, the wisest, the most handsome, the noblest of the three friends, but destiny did not laugh at him. has gained. The heart of the young man, who saw that his friends were wasting the money he needed in the pursuit of his desires, was caught in a fierce struggle between good and evil. Joseph was in distress. This feeling caused him to set foot on his friend's face, to be left alone in wealth and luxury, and to enter the path of betrayal with Zahra, who was looking for a man who would suit his heart and soul. In time, both of them suffered from a guilty conscience, because their psyche could not bear such humiliation. In your student years when those dreams were up to heaven

When the time comes for Yusuf, you will betray your dear friend Mirazim, or Mirazim, who is madly in love with Zahra, will soon leave you alone in the jewels, and would have preferred death to such shame when they said that now you will enter the bosom of Yusuf, whom you respect like a brother. Look at the affairs of the world, today both have committed this abomination, justifying themselves for a number of reasons. But this betrayal did not allow Zahra to have peace of mind, nor did Yusuf to get out of pain. Joseph took the first step to get out of this pit. Zahra was also looking for a way out, and the offer was accepted. They returned to themselves. There was no need for the Russian language either, and an invisible sacred veil was drawn again. 
"Good-bye." Zahra turned her face to the dark side of the car. (It was a sign of kindness. is it not worth sacrificing his life for them.)

Go well, 'said Joseph, not knowing why he had said good-bye.

Yusuf himself could not explain why he started speaking Uzbek and why he started whining, but in any case he felt that he was on the positive side. It had to do with changes in his psyche. Because Joseph's spirit was pure, for he was not a traitor. This was their original image.

\section{CONCLUSION/RECOMMENDATIONS}

Observation of prose works in the Uzbek language shows that in the implementation of poetic communication, researchers often use a type of strategy called "subjectiveanalytical". This strategy is a unique way of modeling real reality, in which the aim of the author of the text is to express his subjective attitude to the referent rather than to describe him through the elements of language. An important nonlinear feature of such a method is that it has a high degree of reader factor.

Indeed, each person's linguistic ability and communication skills are shaped and activated in a particular cultural area, cultural environment. Therefore, it is natural that cultural elements are reflected in the structural and semantic levels of the units that occur in the process of human thinking and linguistic activity.

\section{REFERENCES}

1. Telia V.N. Russian phraseology: semantic, pragmatic and linguocultural aspects. - Moscow:
School "Languages of Russian culture", 1996. - P. 222.

2. Maslova V.A. Linguoculturology: Textbook. allowance. - Moscow: Academia, 2001. - 208 p.

3. Demyankov V.Z. Cognitive linguistics as a kind of interpretive approach // Questions of linguistics, 1994, no. from. 17-33.

4. Zhinkin N.I. Speech as a conductor of information. - Moscow: Nauka, 1982. P. 108

5. Muminov S.M. Socio-linguistic features of Uzbek communication behavior: Philol. fan. d-ri ... dis. avtoref. Tashkent: Academy of Sciences of the Republic of Uzbekistan, 2000. - 47 p.

6. Safarov Sh. Cognitive linguistics. Jizzakh: Sangzor, 2006. - P. 12

7. Krasnykh V. Ethnopsycholinguistics and linguoculturology. - Moscow: Gnosis, 2002. -284 p.

8. Safarov Sh. Pragmalinguistics. Tashkent: "National encyclopedia of Uzbekistan", 2008. - P.59

9. Yuldoshev M. Linguopoetics of literary text. - Tashkent: Fan, 2008. - P. 136.

10. Ulugbek Hamdam. Balance. Tashkent, 2004. - P.179 